Original Research

\title{
Effectiveness of a Shoulder Exercise Program in Division I Collegiate Baseball Players During the Fall Season
}

Hillary A. Plummer, PhD, ATC ${ }^{1}{ }^{\text {a }}$, Shannon M. Plosser, DPT, ATC ${ }^{2}$, Paul R. Diaz, MS, ATC ${ }^{3}$, Nicholas J. Lobb, MS ${ }^{3}$, Lori A. Michener, PhD, PT, ATC, FAPTA ${ }^{3}$

1 U.S. Army Aeromedical Research Laboratory; Oak Ridge Institute for Science \& Education; University of Southern California, 2 University of Southern California, ${ }^{3}$ Division of Biokinesiology and Physical Therapy, University of Southern California

Keywords: shoulder, pitching, injury prevention, evaluation

https://doi.org/10.26603/001c.31638

\section{International Journal of Sports Physical Therapy}

Vol. 17, Issue 2, 2022

\section{Background}

Deficits in shoulder range of motion (ROM) and strength are associated with risk of arm injury in baseball players.

\section{Purpose}

The purpose of this study was to assess the effectiveness of a standardized exercise program, during the fall season, on shoulder ROM and rotational strength in collegiate baseball players.

\section{Study Design}

Prospective cohort study

\section{Methods}

Passive shoulder internal rotation (IR), external rotation (ER), and horizontal adduction ROM were measured with an inclinometer. Shoulder IR and ER strength was assessed using a hand-held dynamometer and normalized to body weight. Players performed a program of shoulder stretching and strengthening exercises, three times/week for one month and then one time/week for two months. Paired sample t-tests compared pre-intervention to post-intervention outcome measures.

\section{Results}

Division I baseball players ( $\mathrm{n}=43 ; 19.6 \pm 1.2$ years, $185.8 \pm 5.5 \mathrm{~cm}, 90.5 \pm 7.0 \mathrm{~kg}$ ) volunteered. From pre- to post-intervention, there were increases in horizontal adduction ROM in the throwing (Mean Difference $(\mathrm{MD})=6.1^{\circ}, 95 \% \mathrm{CI}=3.7,8.5 ; \mathrm{p}<0.001$ ) and non-throwing arm $\left(\mathrm{MD}=8.0^{\circ}, 95 \% \mathrm{CI}=5.6,10.3 ; \mathrm{p}<0.001\right)$, and a decrease in non-throwing arm ER ROM $\left(\mathrm{MD}=2.8^{\circ}, 95 \% \mathrm{CI}=0.2,5.5 ; \mathrm{p}=0.039\right)$. The ER ROM surplus (throwing - non-throwing) increased $\left(\mathrm{MD}=5.6^{\circ}, 95 \% \mathrm{CI}=1.1,10.2 ; \mathrm{p}=0.016\right)$. Throwing $\operatorname{arm}(\mathrm{MD}=1.3 \% \mathrm{BW}$, $95 \% \mathrm{CI}=0.5-2.1, \mathrm{p}=0.003)$ and non-throwing arm $(\mathrm{MD}=1.2 \% \mathrm{BW}, 95 \% \mathrm{CI}=0.4,2.0 ; \mathrm{p}=0.004)$ ER strength decreased. A notable, but non-significant increase in IR strength on the throwing arm $(\mathrm{MD}=1.6 \% \mathrm{BW}, 95 \% \mathrm{CI}=0.1,3.0 ; \mathrm{p}=0.055)$ and decrease on the non-throwing $\operatorname{arm}(\mathrm{MD}=1.2 \% \mathrm{BW}, 95 \% \mathrm{CI}=0.0,2.4 ; \mathrm{p}=0.055)$ occurred. Additionally, throwing arm ER:IR strength ratio $(\mathrm{MD}=0.16,95 \% \mathrm{CI}=0.08,0.25 ; \mathrm{p}<0.001)$ also decreased.

\section{Conclusion}

Changes in shoulder horizontal adduction ROM, IR strength and relative ER surplus on the throwing arm were noted at the end of the season. The lack of change in IR and ER ROM and may be related to the lack of deficits at the start of the fall season.

\footnotetext{
a Corresponding author:

Hillary A. Plummer, PhD, ATC

Oak Ridge Institute for Science \& Education, Oak Ridge, TN, USA hplummer47@gmail.com
} 


\section{Level of Evidence}

2 .

\section{INTRODUCTION}

Upper extremity injuries impact player health and well-being, and can result in time-loss. The shoulder $(21.2 \%)$ and elbow (15.5\%) are injured most frequently in college baseball players. ${ }^{1}$ Strength and range of motion (ROM) deficits have been shown to be related to injury risk and performance. $^{2-4}$ There is limited evidence that structured intervention programs can change modifiable risk factors such as strength and ROM, and the relationship to injury reduction.

Many baseball players have altered shoulder ROM related to humeral retrotorsion and posterior shoulder tissue tightness. ${ }^{5-11}$ While humeral retrotorsion is not modifiable, posterior shoulder tightness that restricts shoulder internal rotation and horizontal adduction ROM can be improved with stretching interventions. ${ }^{12-20}$ Specifically, cross-body stretching and the sleeper stretch have been shown to improve shoulder ROM. ${ }^{12-20}$ Changes in shoulder ROM and strength can occur over the baseball season related to baseball activities. ${ }^{21-24}$ Strengthening interventions may mitigate this decrease in shoulder strength, ${ }^{25}$ shoulder endurance, ${ }^{26}$ and throwing velocity $25,27-29$ in baseball players.

Interventions that target deficits in shoulder ROM and strength may help to reduce injury rates in baseball players. Although some studies indicate that prevention programs may reduce the incidence of injuries, ${ }^{30}$ the research is conflicting in overhead athletes. ${ }^{31}$ Shitara et al. ${ }^{32}$ found that high school baseball pitchers who performed daily posterior shoulder stretching had a lower incidence of upper extremity injury than pitchers who did not perform stretching or strengthening. Pitchers who performed both stretching and external rotation strengthening exercises had similar injury incidence as those who only performed stretching. Youth baseball players performing stretching, dynamic mobility, and balance training had a lower incidence of shoulder and elbow injury in a year than players who did not perform the intervention. ${ }^{33}$ Shoulder horizontal adduction deficits on the non-dominant side also improved with the intervention.

Characterizing the effects of an exercise program on modifiable shoulder-related risk factors in collegiate baseball players is needed. Programs that target deficits in shoulder ROM and strength may lead to a reduction in injuries. The purpose of this study was to assess the effectiveness of a standardized exercise program, during the fall season, on shoulder ROM and rotational strength in collegiate baseball players. It was hypothesized that a standardized exercise program performed over the course of the fall season, would lead to improvements in shoulder ROM and strength.

\section{METHODS}

\section{PARTICIPANTS}

This study was approved by the Institutional Review Board at the University of Southern California. Prior to participa- tion, the procedures, risks, and benefits were explained, and written informed consent was obtained. Data were collected prospectively on Division I collegiate baseball players from a single team however not all of the participants completed every test. Data were collected pre-intervention (August 28, 2017) and post-intervention (November 27, 2017) of the fall season. The fall season, while short, allowed confounding factors of certain players playing more games than others leading to the potential vast differences in player workload that would be present in the spring season to be minimized. Only two competitive baseball games were played during the time of the intervention. Participants were included if they were free from injury at the beginning of the fall season, and on the team roster for the full fall season. Exclusion criteria included not cleared to participate in baseball activities. Data for the players who were not on the team for the full fall season were excluded from the analysis.

An a priori power analysis was conducted using $G^{*}$ Power3 to test the difference between two dependent means using a two-tailed test, an alpha of 0.05 , and a power of 0.8 . An effect size of 0.46 was calculated from previously reported data on the mean difference $\left(4.7^{\circ}\right)$ and standard deviation $\left(10.2^{\circ}\right)$ of glenohumeral internal rotation deficit (pitching arm IR - non-pitching arm IR; GIRD) between injured and non-injured youth pitchers. ${ }^{3}$ It was estimated that a sample size of 39 participants would be needed.

\section{EXERCISE PROGRAM}

Participants performed structured training three times a week from August 29, 2017 to October 3, 2017 under the supervision of a certified strength and conditioning specialist. From October 3, 2017 to November 26, 2017 training was only performed once a week. A comprehensive list of the exercises in the structured training program can be found in Appendix A. Participants performed three to five sets of 5-15 repetitions of the exercises with a load at $70-80 \%$ of their 1-repetition maximum. One-repetition maximum was determined by first estimating a near-maximal load that each athlete could perform two to three repetitions. After a two to three minute break, weight was increased $5-10 \%$ for upper body exercises and 10-20\% for lower body exercises. This process was repeated until the maximal load that an athlete could lift one time was obtained.

\section{PROCEDURES}

A health history form was completed by each participant to assess demographics, injury and surgical history. Shoulder passive ROM and strength were assessed bilaterally.

\section{SHOULDER ROM}

Passive internal rotation (IR), external rotation (ER), and horizontal adduction (HAdd) were measured with a digital inclinometer (Figure 1). The measures were assessed with the participant supine and the shoulder positioned in $90^{\circ}$ of abduction and the elbow flexed $90^{\circ}$. For IR and ER, the in- 
clinometer was placed parallel to the forearm. An examiner placed their hand on the anterior-superior scapula, monitoring scapular position and applying slight overpressure at the end range of each motion. Shoulder HAdd ROM at $90^{\circ}$ of shoulder flexion and the elbow in a relaxed flexed position. An examiner stabilized the lateral border of the scapula and the humerus was moved into horizontal adduction until the lateral border of the scapula moved against the examiner's hand. The inclinometer was aligned parallel to the humerus. Two trials were performed bilaterally for each measure. Data for the two trials were then averaged for analysis. Total ROM (ER + IR), glenohumeral internal rotation deficit (pitching arm IR - non-pitching arm IR; GIRD), and external rotation surplus on the pitching arm (pitching arm ER - non-pitching arm ER; ERS) were calculated from the measured ER and IR values. Interclass correlation coefficient (ICC), standard error of the measure (SEM), and minimal detectable change (MDC90\%) were calculated prior to the start of the study to determine test-retest reliability. Test-retest reliability was established on 10 individuals prior to beginning testing. Shoulder IR ROM had an ICC $(3,2)$ of 0.91 , SEM of $3.4^{\circ}$, and MDC $90 \%$ of $1.4^{\circ}$; ER ROM had an ICC $(3,2)$ of 0.98 , SEM of $0.7^{\circ}$, MDC $90 \%$ of $1.6^{\circ}$, ERS had an ICC $(3,2)$ of 0.96 , SEM of $2.1^{\circ}$, and MDC $90 \%$ of $5.0^{\circ}$; and GIRD had an ICC $(3,2)$ of 0.95 , SEM of $2.2^{\circ}$, and MDC $90 \%$ of $5.2^{\circ}$.

\section{SHOULDER STRENGTH}

Shoulder IR and ER strength were both measured with the participant seated. The arm being tested was positioned by the side, and the elbow flexed to $90^{\circ}$ (Figure 2). A rolled towel was placed between the trunk and the humerus to standardize the positioning and ensure the elbow remained by the side during testing. A handheld dynamometer (Hoggan Scientific, Lafayette, IN) was attached to a specialized stabilizing device and aligned forearm just proximal to the wrist. Two maximal effort isometric contractions with the instructions to 'push as hard as possible for 5 seconds' were performed bilaterally. One minute of rest was allotted between each trial. The mean of the two trials was calculated for data analysis and strength values were normalized to body weight. Test-retest reliability for shoulder isometric strength was established prior to data collection. Testretest reliability for shoulder IR strength indicated an ICC $(3,2)$ of 0.96 , SEM of $0.09 \mathrm{~N} / \mathrm{kg}$, and MDC $90 \%$ of $0.20 \mathrm{~N} / \mathrm{kg}$; and for shoulder ER strength ICC $(3,2)$ of 0.95 , SEM of $0.08 \mathrm{~N} / \mathrm{kg}$, and MDC $90 \%$ of $0.18 \mathrm{~N} / \mathrm{kg}$. For ER:IR, the ICC $(3,2)$ was 0.97 , the SEM was $0.05 \mathrm{~N} / \mathrm{kg}$ and for the MDC $90 \%$ of $0.11 \mathrm{~N} / \mathrm{kg}$.

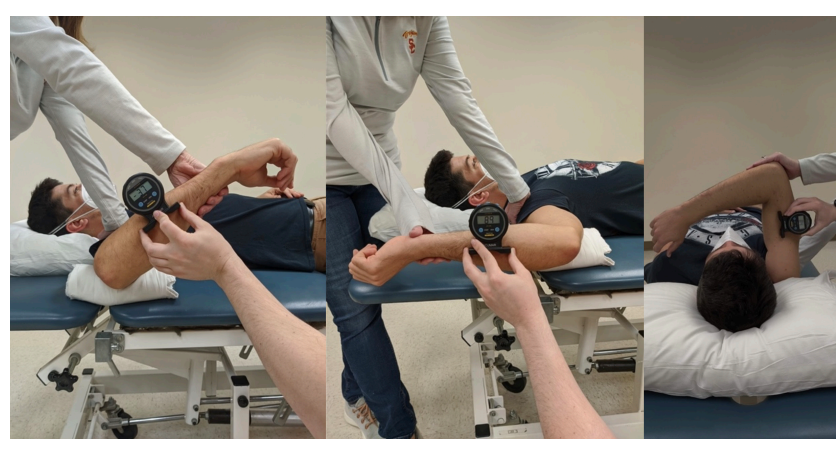

Figure 1. Shoulder range of motion measuresShoulder internal rotation, Shoulder external rotation and Shoulder horizontal adduction.
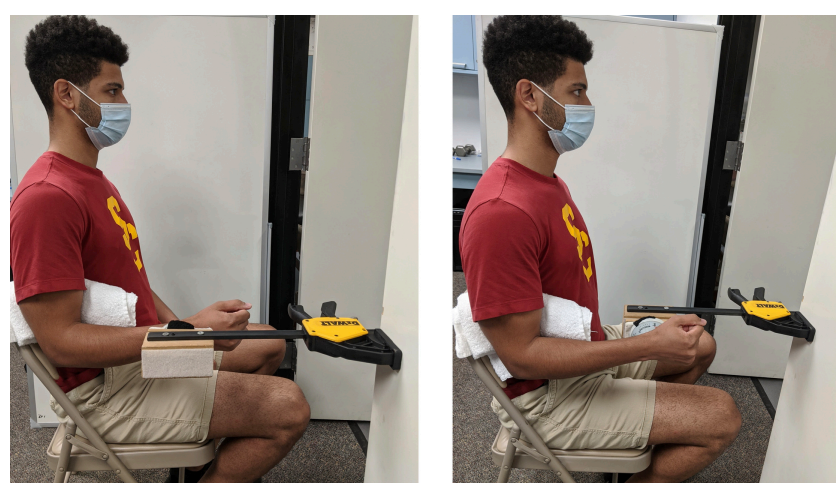

Figure 2. Shoulder strength testing - ER and IR.

\section{STATISTICAL ANALYSIS}

Each dependent variable was averaged across two trials collected for both the pre-intervention and post-intervention data collections. Mean values for each dependent variable were submitted to paired samples t-tests to determine changes in shoulder ROM and strength following the inseason exercise program. Statistical significance was set a priori at $\mathrm{p}<0.05$ and all analyses were performed using RStudio (RStudio Team (2020). RStudio: Integrated Development Environment for R. RStudio, PBC, Boston, MA URL http://www.rstudio.com/). Responders were defined as any participant whose values for a measure exceeded the MDC.

\section{RESULTS}

Data were collected on 43 baseball players $(n=43$, age $=$ 19.6 years, height $=1.86 \mathrm{~m}$, weight $=90.3 \mathrm{~kg}$ ). One participant was lost to follow-up. 
Table 1. Demographics, mean (SD) unless noted $\mathrm{N}$ for throwing arm and position

\begin{tabular}{|c|c|c|c|c|c|c|c|c|c|c|}
\hline \multirow[b]{2}{*}{ Subjects (N) } & \multirow[b]{2}{*}{ Age (yrs) } & \multirow[b]{2}{*}{ Height (cm) } & \multirow[b]{2}{*}{ Weight (kg) } & \multirow[b]{2}{*}{ Yrs Played } & \multicolumn{2}{|c|}{ Throwing Arm (N) } & \multicolumn{4}{|c|}{ Position (N) } \\
\hline & & & & & Right & Left & Pitcher & Catcher & Infield & Outfield \\
\hline 43 & $19.6(1.2)$ & $185.8(5.5)$ & $90.5(7.0)$ & $13.8(2.9)$ & 32 & 11 & 21 & 5 & 13 & 8 \\
\hline
\end{tabular}


Table 2. Shoulder range of motion, mean (SD) and mean differences over time

\begin{tabular}{|c|c|c|c|c|c|}
\hline & & $\begin{array}{l}\text { Pre- } \\
\text { Season }\end{array}$ & $\begin{array}{l}\text { Post- } \\
\text { Season }\end{array}$ & $\begin{array}{c}\mathrm{p}- \\
\text { Value }\end{array}$ & $\begin{array}{l}\text { Mean Difference } \\
\quad(95 \% \mathrm{Cl})\end{array}$ \\
\hline \multirow{4}{*}{ Throwing Arm } & Internal Rotation & $\begin{array}{c}29.7 \\
(10.9)\end{array}$ & $29.7(8.9)$ & 0.979 & - \\
\hline & External Rotation & $\begin{array}{l}109.8 \\
(11.3)\end{array}$ & $\begin{array}{l}112.6 \\
(9.3)\end{array}$ & 0.169 & - \\
\hline & Total (ER+IR) & $\begin{array}{l}140.2 \\
(14.0)\end{array}$ & $\begin{array}{l}142.0 \\
(14.2)\end{array}$ & 0.458 & - \\
\hline & $\begin{array}{l}\text { Horizontal } \\
\text { Adduction }\end{array}$ & $-4.0(6.4)$ & $2.1(5.6)$ & $<0.001$ & $6.1(3.7,8.5)$ \\
\hline \multirow{4}{*}{ Non-Throwing Arm } & Internal Rotation & $36.6(8.6)$ & $37.3(9.0)$ & 0.622 & - \\
\hline & External Rotation & $\begin{array}{l}105.4 \\
(9.9)\end{array}$ & $\begin{array}{l}102.6 \\
(9.1)\end{array}$ & 0.039 & $2.8(0.2,5.5)$ \\
\hline & Total (ER+IR) & $\begin{array}{l}142.0 \\
(13.8)\end{array}$ & $\begin{array}{l}139.9 \\
(11.0)\end{array}$ & 0.326 & - \\
\hline & $\begin{array}{l}\text { Horizontal } \\
\text { Adduction }\end{array}$ & $1.3(4.7)$ & $9.3(8.4)$ & $<0.001$ & $8.0(5.6,10.3)$ \\
\hline \multirow{2}{*}{$\begin{array}{l}\text { Throwing Arm vs Non-Throwing } \\
\text { Arm }\end{array}$} & GIRD & $\begin{array}{c}-6.2 \\
(13.1)\end{array}$ & $-7.9(11.2)$ & 0.368 & - \\
\hline & ERS & $5.4(11.5)$ & $\begin{array}{c}11.0 \\
(10.0)\end{array}$ & 0.016 & $5.6(1.1,10.2)$ \\
\hline
\end{tabular}

Bold font indicates statistical significance.

\section{SHOULDER ROM}

On the throwing arm, only HAdd ROM $(p<0.001)$ significantly increased from pre-intervention to post-intervention (Table 2 \& Figure 3). Seventy-one percent were considered responders to the exercise intervention for HAdd ROM (Figure 3). Internal rotation, ER, and total ROM did not significantly change over time $(p>0.05)$. On the nonthrowing arm, ER ROM decreased $(p=0.039)$ while HAdd ROM increased $(p<0.001)$ from pre-intervention to post-intervention (Table 2). There were no significant differences over time for IR or total ROM $(p>0.05)$. For ERS, there was a significant increase $(p=0.016)$ from pre-intervention to post intervention while no significant change in GIRD $(p>$ 0.05 ) was observed (Table 2). Fifty-six percent of participants were considered responders to the exercise intervention for ERS (Figure 4).

\section{SHOULDER STRENGTH}

On the throwing arm, ER strength $(p=0.003)$ and ER:IR $(p<0.001)$ significantly decreased (Table 3). On the nonthrowing arm, ER strength also decreased $(p=0.004)$, but no change in ER:IR strength ratio was observed $(p>0.05)$. A notable increase in IR strength on the throwing arm and decrease on the non-throwing arm was observed, but neither change was significant ( $p=0.055$ for both). Fifty-seven percent of participants were considered responders to the exercise intervention for IR strength (Figure 5). When comparing the strength of the throwing arm to the non-throwing arm, the IR strength ratio between arms significantly increased $(p<0.001)$, indicating an increase in IR strength in

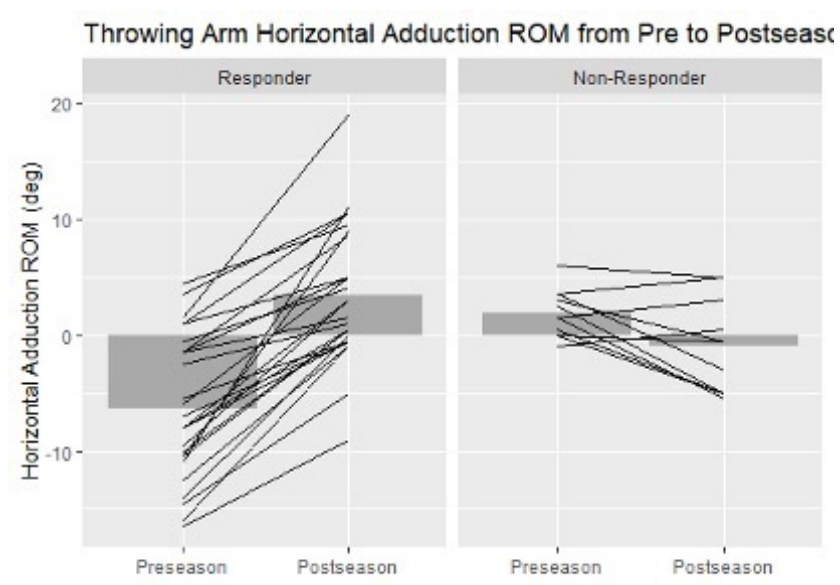

Figure 3. Individual responsiveness of shoulder horizontal adduction range of motion to the intervention.

Black lines indicate individual responses for horizontal adduction range of motion and grey bars show the mean group values. Responders exceeded the minimal detectable change indicating changes were not due to measurement error.

the throwing arm relative to the non-throwing arm, but no significant difference was observed in the ER strength ratio (Table 3).

\section{DISCUSSION}

A standardized exercise program successfully increased 
Table 3. Shoulder strength (N/kg), mean (SD) and mean differences over time

\begin{tabular}{|c|c|c|c|c|c|}
\hline & & $\begin{array}{l}\text { Pre- } \\
\text { Season }\end{array}$ & $\begin{array}{l}\text { Post- } \\
\text { Season }\end{array}$ & $\begin{array}{c}\mathrm{p}- \\
\text { Value }\end{array}$ & $\begin{array}{l}\text { Mean Difference }(95 \% \\
\mathrm{CI})\end{array}$ \\
\hline \multirow{3}{*}{ Throwing Arm } & $\begin{array}{l}\text { External } \\
\text { Rotation }\end{array}$ & $\begin{array}{c}1.47 \\
(0.28)\end{array}$ & $1.34(0.25)$ & 0.003 & $0.13(0.05,0.21)$ \\
\hline & $\begin{array}{l}\text { Internal } \\
\text { Rotation }\end{array}$ & $\begin{array}{c}1.78 \\
(0.48)\end{array}$ & $19.7(1.93)$ & 0.055 & $0.16(0.01,0.29)$ \\
\hline & ER:IR Ratio & $\begin{array}{c}0.88 \\
(0.26)\end{array}$ & $0.71(0.14)$ & $<0.001$ & $0.17(0.08,0.25)$ \\
\hline \multirow{3}{*}{ Non-Throwing Arm } & $\begin{array}{l}\text { External } \\
\text { Rotation }\end{array}$ & $\begin{array}{c}1.51 \\
(0.23)\end{array}$ & $1.39(0.26)$ & 0.004 & $0.12(0.04,0.20)$ \\
\hline & $\begin{array}{l}\text { Internal } \\
\text { Rotation }\end{array}$ & $\begin{array}{c}1.96 \\
(0.39)\end{array}$ & $1.84(0.39)$ & 0.055 & $0.12(0.00,0.24)$ \\
\hline & ER:IR Ratio & $\begin{array}{c}0.79 \\
(0.14)\end{array}$ & $0.77(0.15)$ & 0.64 & - \\
\hline \multirow{2}{*}{$\begin{array}{l}\text { Throwing Arm vs Non-Throwing } \\
\text { Arm }\end{array}$} & $\begin{array}{r}\text { IR Strength } \\
\text { Ratio }\end{array}$ & $\begin{array}{c}0.92 \\
(0.19)\end{array}$ & $1.09(0.18)$ & $<0.001$ & $0.17(0.08,0.27)$ \\
\hline & $\begin{array}{r}\text { ER Strength } \\
\text { Ratio }\end{array}$ & $\begin{array}{c}0.99 \\
(0.18)\end{array}$ & $0.99(0.20)$ & 0.872 & - \\
\hline
\end{tabular}

Bold font indicates statistical significance.

shoulder HAdd ROM from pre-intervention to post-intervention in collegiate baseball players. Additionally, ERS increased from pre- to post-intervention, indicating greater ER surplus on the throwing arm. Half of the participants (56\%) demonstrated a meaningful increase in ERS following the intervention. Contrary to the hypothesis, a decrease in shoulder ER strength and ER:IR strength ratio also occurred. Athlete exposure to baseball participation can result in both acute and chronic adaptations to ROM and strength of the shoulder. ${ }^{21,23,24,34}$ Exercise interventions that maintain or increase ROM and can counteract the physiological adaptations that may occur as a result of baseball participation. ${ }^{21}$ These results indicate that a standardized exercise program performed throughout the season may be beneficial for targeting certain modifiable physical factors to maintain and limit the loss of strength. Targeting modifiable factors such as shoulder ROM and strength through an exercise intervention program may help to reduce injury risks in baseball players, however this aim is outside the scope of preliminary investigation.

Shoulder HAdd ROM, which assesses posterior shoulder tightness, was the only shoulder ROM variable that changed following the intervention on the throwing arm. A majority of the participants (71\%) demonstrated a meaningful increase in HAdd following the intervention but some may have had limitations to begin with. There was a $6.1^{\circ}$ increase in the HAdd from pre to post-intervention, which exceeds measurement error (MDC90\%) of $4.2^{\circ}$ for passive HAdd. ${ }^{2}$ A similar noted increase in HAdd ranging between $15.7^{\circ}$ and $17.5^{\circ}$ in professional baseball players from pre to post-intervention. ${ }^{35,36}$ While Chan et al. ${ }^{35}$ did not provide an intervention, all players participated in posterior shoulder stretching drills which may have accounted for their observations. McGraw et al. ${ }^{36}$ provided a stretching and mobilization intervention, but only for athletes that exhibited a deficit in ER, IR, or HAdd in their throwing arm compared to

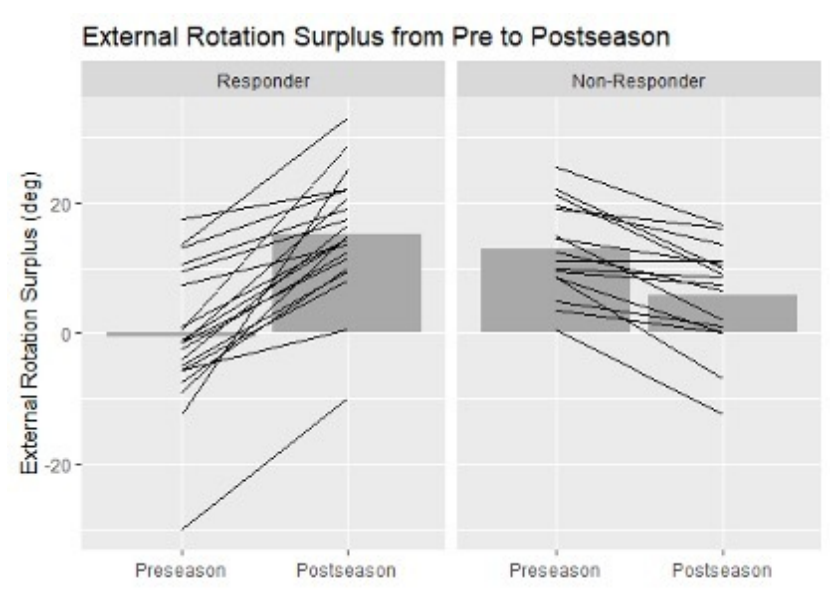

Figure 4. Individual responsiveness of shoulder external rotation surplus range of motion to the intervention.

Black lines indicate individual responses for external rotation surplus and grey bars show the mean group values. Responders exceeded the minimal detectable change indicating changes were not due to measurement error.

their non-throwing arm. The current intervention similarly included soft tissue mobilization of the posterior shoulder musculature with a lacrosse ball or Theragun (Therabody, Los Angeles, CA), as well as cross-body stretching, yet increases in Hadd were less than half that of previous literature. It is possible that the difference in competitive levels and temporal factors partially accounted for this discrepancy. Both Chan et al. ${ }^{35}$ and McGraw et al. ${ }^{36}$ studied professional athletes whose seasons last six to seven months. The athletes in this study were tested before and after their fall season which only lasted two months.

Contrary to the hypothesis, no changes in IR, ER, or total 
ROM (IR+ER) were observed on the throwing arm. In professional pitchers, decreased shoulder IR and total ROM have been observed for up to 24 hours after pitching, ${ }^{21}$ but the findings on long-term changes are inconsistent. Dwelly et al. ${ }^{22}$ found that ER ROM significantly increased by $2.9^{\circ}$ from preseason to postseason in collegiate pitchers, but Freehill et al. ${ }^{34}$ found no changes in ER, IR or total ROM for professional pitchers.

Considering the effectiveness of posterior rotator cuff and cross-body stretching routines, it appears that the stretching intervention in the present study may have countered any acute changes in IR ROM typically observed, but did not further increase IR ROM beyond its preseason value. ${ }^{12,19,36}$ The current intervention did not further affect the players ROM beyond each pitcher's normal arm care program. Deficits in total ROM are related to shoulder and elbow injury. ${ }^{37-39}$ However, no changes in total ROM were observed in this study. This result may have been due to players having a high total ROM of $140^{\circ}$ prior to the exercise program so large improvements were not expected due to a ceiling effect. Total ROM was similar to what has previously been reported in collegiate baseball and softball players. ${ }^{22}$

When comparing between arms, the hypothesis was partially supported. No change in GIRD was observed, but ER surplus improved as noted with an improved ERS of $5.6^{\circ}$. The increased ERS was driven by an increase of $2.7^{\circ}$ in the throwing arm ER with accompanying decrease of $2.8^{\circ} \mathrm{ER}$ in the non-throwing arm. The change in ERS exceeded the MDC $90 \%$ of $1.6^{\circ}$ indicating the change was likely meaningful and not due to measurement error. A lack of ERS on the throwing arm has been identified as a risk factor for injury in baseball players. ${ }^{4}$ Specifically, those who exhibit less than $5^{\circ}$ surplus of ER ROM on their throwing arm compared to their non-throwing arm are 1.9 times as likely to suffer an upper extremity injury. 4

The ratio of ER:IR strength ranges from $63-98 \%$ in the throwing arm of healthy baseball players. ${ }^{26,40-43}$ Baseball players in the current study had ER:IR strength ratio decreased from $88 \%$ to $71 \%$ over the course of the season. The ratio decreased due to players having a decrease in throwing arm shoulder ER strength and a notable, but insignificant, increase in shoulder IR strength. However, while the change in ER:IR ratio exceeded its MDC value, the changes in its constituents did not exceed their respective MDC values, and therefore may have been caused by measurement error. The decrease in shoulder ER strength could be related to a decrease in the frequency of training as the season progressed. Players were initially participating in training three times a week following testing and then training decreased to once a week. The internal rotators were not adversely affected by the change in the training schedule, which may be due to their role during throwing. The ER muscles act eccentrically during the deceleration phase of throwing whereas the IR muscles are required to work both concentrically and eccentrically throughout the throwing motion. ${ }^{44}$ Therefore, the difference in loading of the IR muscles compared to ER muscles may account for the observed changes in strength. Half of the participants (57\%) demonstrated a meaningful increase in IR strength. Considering the changes in ER and IR strength were smaller than their respective MDC values, the use of any arm care inter-

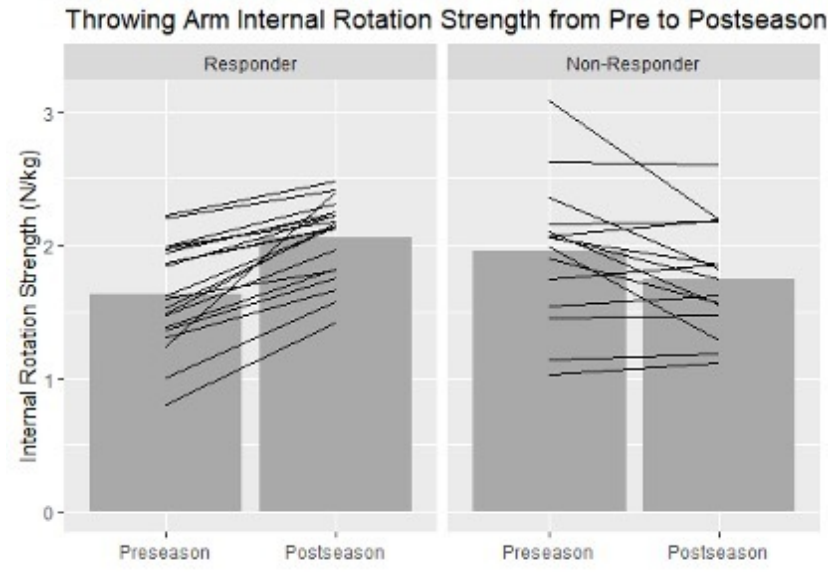

\section{Figure 5. Individual responsiveness of throwing arm} internal rotation strength to the intervention.

Black lines indicate individual responses for internal rotation strength and grey bars show the mean group values. Responders exceeded the minimal detectable change indicating changes were not due to measurement error.

ventions to maintain or build strength during the season should be further investigated. A longer intervention would likely have been beneficial for improving strength but was logistically challenging with the cohort of Division I players. The athletes are restricted to the number of hours they can participate in training and practice each week.

Shoulder isokinetic strength changes have been observed following the season in high school pitchers. ${ }^{23,45}$ Whitley et al. ${ }^{23}$ found that shoulder HAdd and shoulder IR strength decreased in the throwing and non-throwing arm, however ER strength did not change. The intervention they used may have been helpful in increasing IR strength but not ER strength. ${ }^{23}$ When evaluating the exercises they prescribed for the players, the players primarily performed dynamic and compound exercises. ${ }^{23}$ Lack of isolated strengthening of the external rotators may have contributed to the decreased ER strength. In a study evaluating upper extremity muscular endurance on baseball players during a 20-week pre-season training program, increased posterior shoulder muscular endurance was observed. ${ }^{26}$ The exercises behind this change, during the 20-weeks, consisted of low resistance and high repetition with a combination of both isolated and compound exercises. ${ }^{26}$ Therefore, incorporating more isolated strengthening of the external rotators with emphasis on endurance may be important to sustain strength in these muscles over the course of a season. It is also possible that testing strength eccentrically may have resulted in differences following the training program since this may more closely relate to the demands of throwing.

Muscle activation for various iterations of most of the exercises used in the current intervention have been examined. Low (0-20\% maximal voluntary isometric contraction) to moderate (21-40\% maximal voluntary isometric contraction) level activation of the rotator cuff and scapular stabilizer muscles have been observed for most of the exercises in healthy non-overhead athletes. ${ }^{46,47}$ High muscle activation exercises may be more effective in improving isometric strength in overhead athletes but evidence of this is limited. 
Of the electromyography studies reported in the literature, most are done in healthy non-overhead athletes and not baseball players therefore it limits their generalizability to baseball players.

The outcome assessment for muscle performance in this study was isometric strength with a hand-held dynamometer. Clearly, this is just one aspect of muscle performance. The exercises may be influencing neuromuscular factors that were not assessed with the outcome measure of isometric strength. Perhaps it is not the exercises but rather the outcome assessment that contributed to the lack of observed changes. It is also possible that large changes in strength in high level athletes during the season do not occur and maybe the changes were not strength related but due to rate of force development. Rate of force development is the rate that and individual can generate maximal force production during a given activity. ${ }^{48}$ Rate of force development utilizes the stretch-shortening cycle of a muscle and is optimized when maximal force is produced in the shortest amount of time possible. ${ }^{48}$ The methods used in the current study were not able to assess the influence of rate of force development but should be considered in the future.

This study has limitations. Data were collected on a single Division I baseball team, limiting generalizability to other levels of competition. It is unknown if players did additional exercises beyond what they were prescribed by the strength and conditioning specialist. Without a control group, the authors cannot assert that the changes observed were due solely to the training. It is possible that players had ROM or strength adaptations that occurred due to baseball participation. ${ }^{22}$ This study was a preliminary investigation designed to test the exercise program and obtain pilot data for a future randomized controlled trial. The goal of a future randomized controlled trial would be to determine the effectiveness on injury rates. The fall season was chosen because college baseball teams focus more on practice and strength training during this time period in order to prepare for the competitive spring season. During the spring season, the focus of strength training programs moves into a maintenance phase of the periodized programming due to the number of competitive games that are played during this period. The results may have been different had changes in shoulder ROM and strength, been examined during the spring season. However, performing this study during the spring season would have introduced the confounding factors of athlete exposure to the demands of playing baseball during more games as some players who are starters would have greater exposure than players who compete less frequently. With less games being played in the fall season there was potentially less undue influence of athlete exposure on the results. Alternatively, the dosing and duration of the program may not have been adequate to elicit change in some variables.

\section{CONCLUSIONS}

Performing a standardized exercise program was demonstrated to be beneficial for improving shoulder HAdd ROM and ERS (improving the relative amount of ER on the throwing arm) in collegiate baseball players. Baseball players often present with altered ROM and strength patterns due to the frequency and repetitive nature of the sport. Being able to effectively target shoulder musculature to improve ROM and strength may help to decrease the incidence of injury and improve performance. The lack of change in IR and ER ROM may be related to the lack of deficits at the start of the season.

\section{ETHICS APPROVAL}

The University of Southern California Institutional Review Board approved this study.

\section{ACKNOWLEDGEMENTS}

This research was supported in part by an appointment to the postgraduate research program at the U.S. Army Aeromedical Research Laboratory administered by Oak Ridge Institute for Science and Education through an interagency agreement between the U.S. Department of Energy and the U.S. Army Medical Research and Development Command.

\section{DISCLAIMER}

The views, opinions, and/or findings contained in this report are those of the author(s) and should not be construed as an official Department of the Army position, policy, or decision, unless so designated by other official documentation. Citation of trade names in this report does not constitute an official Department of the Army endorsement or approval of the use of such commercial items.

Submitted: April 20, 2021 CST, Accepted: November 19, 2021 CST 


\section{REFERENCES}

1. Wasserman EB, Register-Mihalik JK, Sauers EL, et al. The first decade of web-based sports injury surveillance: Descriptive epidemiology of injuries in US high school girls' softball (2005-2006 through 2013-2014) and National Collegiate Athletic Association Women's Softball (2004-2005 through 2013-2014). J Athl Train. 2019;54(2):212-225. doi:10.4 085/1062-6050-206-17

2. Shanley E, Kissenberth MJ, Thigpen CA, et al. Preseason shoulder range of motion screening as a predictor of injury among youth and adolescent baseball pitchers. J Shoulder Elbow Surg. 2015;24(7):1005-1013. doi:10.1016/j.jse.2015.03.012

3. Shanley E, Rauh MJ, Michener LA, Ellenbecker TS, Garrison JC, Thigpen CA. Shoulder range of motion measures as risk factors for shoulder and elbow injuries in high school softball and baseball players. Am J Sports Med. 2011;39(9):1997-2006. doi:10.1177/0 $\underline{363546511408876}$

4. Pozzi F, Plummer HA, Shanley E, et al. Preseason shoulder range of motion screening and in-season risk of shoulder and elbow injuries in overhead athletes: a systematic review and meta-analysis. $\mathrm{Br} \mathrm{J}$ Sports Med. 2020;54(17):1019-1027. doi:10.1136/bjspo rts-2019-100698

5. Crockett HC, Gross LB, Wilk KE, et al. Osseous adaptation and range of motion at the glenohumeral joint in professional baseball pitchers. Am J Sports Med. 2002;30(1):20-28.

6. Chant CB, Litchfield R, Griffin S, Thain LM. Humeral head retroversion in competitive baseball players and its relationship to glenohumeral rotation range of motion. J Orthop Sports Phys Ther. 2007;37(9):514-520. doi:10.2519/jospt.2007.2449

7. Tokish JM, Curtin MS, Kim YK, Hawkins RJ, Torry MR. Glenohumeral internal rotation deficit in the asymptomatic professional pitcher and its relationship to humeral retroversion. J Sports Sci Med. 2008;7:78-83.

8. Thomas SJ, Swanik CB, Higginson JS, et al. A bilateral comparison of posterior capsule thickness and its correlation with glenohumeral range of motion and scapular upward rotation in collegiate baseball players. J Shoulder Elbow Surg. 2011;20(5):708-716. doi:10.1016/i.jse.2010.08.031

9. Thomas SJ, Swanik CB, Kaminski TW, et al. Humeral retroversion and its association with posterior capsule thickness in collegiate baseball players. J Shoulder Elbow Surg. 2012;21(7):910-916. do i:10.1016/j.jse.2011.05.028
10. Noonan TJ, Shanley E, Bailey LB, et al. Professional pitchers with glenohumeral internal rotation deficit (GIRD) display greater humeral retrotorsion than pitchers without GIRD. Am J Sports Med. 2015;43(6):1448-1454. doi:10.1177/0363546515 $\underline{575020}$

11. Hibberd EE, Oyama S, Myers JB. Increase in humeral retrotorsion accounts for age-related increase in glenohumeral internal rotation deficit in youth and adolescent baseball players. Am J Sports Med. 2014;42(4):851-858. doi:10.1177/036354651351 9325

12. McClure P, Balaicuis J, Heiland D, Broersma ME, Thorndike CK, Wood A. A randomized controlled comparison of stretching procedures for posterior shoulder tightness. J Orthop Sports Phys Ther. 2007;37(3):108-114.

13. Laudner KG, Sipes RC, Wilson JT. The acute effects of sleeper stretches on shoulder range of motion. J Athl Train. 2008;43(4):359-363.

14. Tyler TF, Nicholas SJ, Lee SJ, Mullaney M, McHugh MP. Correction of posterior shoulder tightness is associated with symptom resolution in patients with internal impingement. Am J Sports Med. 2010;38(1):114-119. doi:10.1177/0363546509346050

15. Bailey LB, Thigpen CA, Hawkins RJ, Beattie PF, Shanley E. Effectiveness of manual therapy and stretching for baseball players with shoulder range of motion deficits. Sports Health. 2017;9(3):230-237. do $\mathrm{i}: 10.1177 / 1941738117702835$

16. Maenhout A, Van Eessel V, Van Dyck L, Vanraes A, Cools A. Quantifying acromiohumeral distance in overhead athletes with glenohumeral internal rotation loss and the influence of a stretching program. Am J Sports Med. 2012;40(9):2105-2112. do i:10.1177/0363546512454530

17. Oyama S, Goerger CP, Goerger BM, Lephart SM, Myers JB. Effects of non-assisted posterior shoulder stretches on shoulder range of motion among collegiate baseball pitchers. Athl Train Sports Health Care. 2010;2(4):163-170. doi:10.3928/19425864-2010 $\underline{0524-01}$

18. Yamauchi T, Hasegawa S, Nakamura M, et al. Effects of two stretching methods on shoulder range of motion and muscle stiffness in baseball players with posterior shoulder tightness: A randomized controlled trial. J Shoulder Elbow Surg. 2016;25(9):1395-1403. doi:10.1016/j.jse.2016.04.025 
19. Kang MH, Oh JS. Effects of self-stretching with mobilization on shoulder range of motion in individuals with glenohumeral internal rotation deficits: a randomized controlled trial. J Shoulder Elbow Surg. 2020;29(1):36-43. doi:10.1016/j.jse.201 $\underline{9.08 .007}$

20. Sauers E, August A, Snyder A. Fauls stretching routine produces acute gains in throwing shoulder mobility in collegiate baseball players. J Sport Rehabil. 2007;16(1):28-40.

21. Reinold MM, Wilk KE, Macrina LC, et al. Changes in shoulder and elbow passive range of motion after pitching in professional baseball players. Am J Sports Med. 2008;36(3):523-527. doi:10.1177/0363546507308 $\underline{935}$

22. Dwelly PM, Tripp BL, Tripp PA, Eberman LE, Gorin $S$. Glenohumeral rotational range of motion in collegiate overhead-throwing athletes during an athletic season. J Athl Train. 2009;44(6):611-616.

23. Whitley JD, Terrio T. Changes in peak torque armshoulder strength of high school baseball pitchers during the season. Percept Mot Skills. 1998;86(3 Pt 2):1361-1362.

24. Bido J, Gibbons MW, Kraszewski A, et al. The effect of pitch count on shoulder kinematics and strength in adolescent baseball pitchers. J Shoulder Elbow Surg. 2014;23(9):E32.

25. Wooden MJ, Greenfield B, Johanson M, Litzelman L, Mundrane M, Donatelli RA. Effects of strength training on throwing velocity and shoulder muscle performance in teenage baseball players. J Orthop Sports Phys Ther. 1992;15(5):223-228. doi:10.2519/jos pt.1992.15.5.223

26. Moore SD, Uhl TL, Kibler WB. Improvements in shoulder endurance following a baseball-specific strengthening program in high school baseball players. Sports Health. 2013;5(3):233-238. doi:10.117 $\underline{7 / 1941738113477604}$

27. Escamilla RF, Fleisig GS, Yamashiro K, et al. Effects of a 4-week youth baseball conditioning program on throwing velocity. J Strength Cond Res. 2010;24(12):3247-3254. doi:10.1519/ISC.0b013e3181d b9f59

28. Escamilla RE, Ionno M, deMahy MS, et al. Comparision of three baseball-specific 6-week training programs on throwing velocity in high school baseball players. J Strength Cond Res.

2012;26(7):1767-1781.
29. Carter AB, Kaminski TW, Douex AT Jr, Knight CA, Richards JG. Effects of high volume upper extremity plyometric training on throwing velocity and functional strength ratios of the shoulder rotators in collegiate baseball players. J Strength Cond Res. 2007;21(1):208-215. doi:10.1519/R-19315.1

30. Aldridge R, Guffey JS, Whitehead MT, Head P. The effects of a daily stretching protocol on passive glenohumeral internal rotation in overhead throwing collegiate athletes. Int J Sports Phys Ther. 2012;7(4):365-371.

31. Cools AM, Johansson FR, Borms D, Maenhout A. Prevention of shoulder injuries in overhead athletes: A science-based approach. Braz J Phy Ther. 2015;19(5):331-339. doi:10.1590/bjpt-rbf.2014.0109

32. Shitara H, Yamamoto A, Shimoyama D, et al. Shoulder stretching intervention reduces the incidence of shoulder and elbow injuries in high school baseball players: A time-to-event analysis. Sci Rep. 2017;7:45304.

33. Sakata J, Nakamura E, Suzuki T, et al. Efficacy of a prevention program for medial elbow injuries in youth baseball players. Am J Sports Med. Published online 2017:460-469. doi:10.1177/0363546517738003

34. Freehill MT, Ebel BG, Archer KR, et al. Glenohumeral range of motion in Major League pitchers: changes over the playing season. Sports Health. 2011;3(1):97-104. doi:10.1177/1941738110374 $\underline{627}$

35. Chan JM, Zajac J, Erickson BJ, et al. Upper extremity and hip range of motion changes throughout a season in professional baseball players. Am J Sports Med. 2020;48(2):481-487.

36. McGraw MH, Vrla M, Wang D, et al. Shoulder and elbow range of motion can be maintained in Major League Baseball pitchers over the course of the season, regardless of pitching workload. Orthop J Sports Med. 2019;7(2):2325967118825066. doi:10.117 $\underline{7 / 2325967118825066}$

37. Bullock GS, Faherty MS, Ledbetter L, Thigpen CA, Sell TC. Shoulder range of motion and with baseball arm injuries: A systematic review and meta-analysis. J Athl Train. 2018;53(12):1190-1199. doi:10.4085/106 2-6050-439-17

38. Wilk KE, Macrina LC, Fleisig GS, et al. Correlation of glenohumeral internal rotation deficit and total rotational motion to shoulder injuries in professional baseball pitchers. Am J Sports Med. 2011;39(2):329-335. doi:10.1177/0363546510384223 
39. Wilk KE, Macrina LC, Fleisig GS, et al. Deficits in glenohumeral passive range of motion increase risk of elbow injury in professional baseball pitchers: A prospective study. Am J Sports Med. 2014;42(9):2075-2081. doi:10.1177/036354651453839 1

40. Byram IR, Bushnell BD, Dugger K, Charron K, Harrell FE Jr, Noonan TJ. Preseason shoulder strength measurements in professional baseball pitchers: identifying players at risk for injury. Am J Sports Med. 2010;38(7):1375-1382. doi:10.1177/036354650936040 4

41. Brown LP, Niehues SL, Harrah A, Yavorsky P, Hirshman HP. Upper extremity range of motion and isokinetic strength of the internal and external shoulder rotators in Major League Baseball Players. Am J Sports Med. 1988;16(6):577-585.

42. Ellenbecker TS, Mattalino AJ. Concentric isokinetic shoulder internal and external rotation strength in professional baseball pitchers. J Orthop Sports Phys Ther. 1997;25(5):323-328.

43. Donatelli R, Ellenbecker TS, Ekedahl SR, Wilkes JS, Kocher K, Adam J. Assessment of shoulder strength in professional baseball pitchers. J Orthop Sports Phys Ther. 2000;30(9):544-551.
44. Noffal GJ. Isokinetic eccentric-to-concentric strength ratios of the shoulder rotator muscles in throwers and nonthrowers. Am J Sports Med. 2003;31(4):537-541.

45. Wilkin LD, Haddock BL. Isokinetic strength of collegiate baseball pitchers during a season. J Strength Cond Res. 2006;20(4):829-832. doi:10.1519/R-18045.1

46. Pozzi F, Plummer HA, Sanchez N, Lee Y, Michener LA. Electromyography activation of shoulder and trunk muscles is greater during closed chain compared to open chain exercises. J Electromyogr Kinesiol. Published online 2019. doi:10.1016/i.jeleki n.2019.05.007

47. Edwards PK, Ebert JR, Littlewood C, Ackland T, Wang A. A systematic review of electromyography studies in normal shoulders to inform postoperative rehabilitation following rotator cuff repair. J Orthop Sports Phys Ther. 2017;47(12):931-944. doi:10.2519/jo spt.2017.7271

48. Aagaard P, Simonsen EB, Andersen JL, Magnusson $\mathrm{P}$, Dyhre-Poulsen P. Increased rate of force development and neural drive of human skeleton muscle following resistance training. J Appl Physiol. 2002;93:1318-1326. 


\section{SUPPLEMENTARY MATERIALS}

\section{Appendix 1}

Download: https://ijspt.scholasticahq.com/article/31638-effectiveness-of-a-shoulder-exercise-program-in-division-icollegiate-baseball-players-during-the-fall-season/attachment/79407.docx?auth token=2aHCUVULVyy2B-Pa1aCl 